\title{
PKM Pelatihan Sistem Akademik Berbasis Web di Madrasah Diniah Nurul Amin
}

\author{
Hasbul Bahar ${ }^{1}$, Muhammad Habibullah², Anton Wijaya ${ }^{3}$, Hasan Basori ${ }^{4}$,
} Alin Widodo ${ }^{5}$, Ahmad Abdur Rahim ${ }^{6}$, Ubaydillah ${ }^{7}$

Universitas Nurul Jadid, Teknik Informatika ${ }^{1,2,3,4,5,6,7,8}$

\{ hasbulbahar@unuja.ac.id ${ }^{1}$, Muh.Habib3290@gmail.com ${ }^{2}$,AntonWijaya44@gmail.com4 Ha5an32@gmail.com5, alinW7@gmail.com6, AARahim71@gmail.com7, Ubaydillah31@gmail.com ${ }^{8}$

Submission: 26/09/2021 Received: 31/12/2021 Published: 31/12/2021

\section{Keywords:}

Mentoring,

Information

Systems,

Workshops,

Simulations
Abstract. This dedication to Madrasah is a follow-up to research on Integrated Responsive Web-Based Academic Applications with the Import Export Excel System. Madrasah Diniah Nurul Amin has a structure which contains data from teachers, students, and also the teaching and learning system. The purpose of the structure is to advance the teaching and learning system at Madrasah Diniah Nurul Amin. However, what is often a problem in general is the limitation of data processing to filter (filter) different teacher and student data, starting from new and old teacher and student data, and inefficient lesson schedule arrangements so that we often encounter problems such as teachers who forget the time of teaching hours and what lessons should be taught, as well as students, they also often forget the time and subjects that will be studied. This is one of the processes of interaction between the internal parts of the school Madrasah Diniah Nurul Amin or educational institutions that process data with certain processes and procedures, with users who in this case are operators. Therefore, this Responsive Web-Based Academic Application Integrated with the Import Export Excel System is needed to make it easier to provide accurate data information including: (1) Facilitating the Data Processing Process (2) As an Information Center for teachers and students (3) Provide Reports on the Progress of Teaching and Learning Activities (4) Madrasas are more Up To Date (5) Improve the Image of Madrasas (6) Students Can Know Academic Information Anytime and Anywhere, (7) Comprehensive Reports (8) Facilitate academic staff (9) As guidance in formulating madrasa policies (10) facilitating and accelerating registration and her registration (11) Students can see the value through the academic website application so that it is faster and many other things. So that they can provide good, efficient service and make sure there will be no confusion between teachers and students at Madrasah Diniah Nurul Amin. 
Katakunci:

Pendampingan, Sistem Informasi, Workshop, Simulasi

\begin{abstract}
Abstrak. Pengabdian kepada Madrasah tersebut merupakan tindak lanjut dari penelitian tentang Aplikasi Akademik Berbasis Web Responsive Terintergrasi dengan Sistem Import Export Excel. Madrasah Diniah Nurul Amin mempunyai sebuah struktur yang mana di dalamnya ber isi data-data mulai dari para Guru, Muridmurid, dan juga Sistem Belajar Mengajarnya. Tujuan di buatnya stuktur tersebut adalah untuk memajukan sistem belajar mengajar di Madrasah Diniah Nurul Amin. Akan tetapi yang sering kali menjadi permasalahan pada umumnya adalah keterbatasan pengolahan data-data untuk memfilter (menyaring) data-data guru dan murid yang berbeda,mulai dari data guru dan murid yang baru maupun yang telah lama, dan pengaturan jadwal pelajaran yang kurang efesien sehingga kita sering menjumpai masalah seperti halnya guru yang lupa waktu jam mengajar dan pelajaran apa yang harus di ajarkannya,demikian pula dengan murid,mereka juga sering lupa akan waktu dan mata pelajaran yang akan di pelajarinya.Hal tersebut merupakan salah satu proses interaksi antara bagian internal sekolah Madrasah Diniah Nurul Amin ataupun lembaga pendidikan yang mengolah data dengan proses serta prosedur-prosedur tertentu, dengan user yang dalam hal ini adalah operator. Maka dari itu Aplikasi Akademik Berbasis Web Responsive Terintergrasi dengan Sistem Import Export Excel ini di butuhkan agar mempermudah dalam memberikan informasi datadata yang akurat di antaranya: (1) Memudahkan Proses Pengolahan Data (2) Sebagai Pusat Informasi para guru dan murid(3) Memberikan Laporan Perkembangan Kegiatan Belajar Mengajar (4) Madrasah lebih Up To Date (5) Meningkatkan Citra Madrasah (6) Murid Dapat Mengetahui Informasi Akademik Kapan Saja Dan Dimana saja, (7) Laporan yang komprehensif (8) Memudahkan petugas akademik (9) Sebagai panduan dalam menyusun kebijakan madrasah (10) memudahkan dan mempercepat registrasi dan her registrasi (11) Murid dapat melihat nilainya melalui aplikasi Website akademik sehingga lebih cepat dan masih banyak hal lainnya.Sehingga dapat memberika layanan yang baik, efisien dan di pastikan tidak akan terjadi kebingungan antara guru dan murid di Madrasah Diniah Nurul Amin.
\end{abstract}

\section{Pendahuluan}

Sistem Aplikasi Akademik Berbasis Website Di Madrasah Diniah Nurul Amin Jabung bertujuan untuk mendukung penyelengaraan pendidikan, sehingga dari pengelolahan data tersebut akan menghasilkan data-data informasi yang lebih efisien, efektif, praktis dan berguna untuk murid, guru maupun lembaga itu sendiri untuk memajukan Akreditasi Pendidikan Di Madrasah Diniah Nurul Amin. Namun tidak semua madrasah diniah sudah menerapkan sistem informasi akademik. Sama halnya dengan Madrasah Diniah yang lain, Madrasah Diniah Nurul Amin Jabung merupakan madrasah 
diniah yang belum memiliki sistem informasi akademik berbasis website dalam mengelola kegiatan Belajar Mengajar. Sehingga pengolahan data-data kelembagaan sekolah tersebut kurang akuarat dan efesien. Dengan perkembangan teknologi saat ini kebutuhan terhadap informasi sangatlah penting sehingga informasi harus dapat diakses kapan saja dan dimana saja. dan untuk mengatasi masalah-masalah tersebut, maka peranan sistem informasi akademik sangat dibutuhkan oleh Madrasah Diniah Nurul Amin Jabung. Dengan adanya sistem informasi akademik diharapkan bagian akademik Madrasah Diniah Nurul Amin Jabung dapat meningkatkan pelayanan terhadap para murid, guru maupun orang tua murid.

Salah satu sistem informasi Madrasah yang dapat membantu mMadrasah sebagai Madrasah berbasis Web adalah Siakad Enterprise, sistem akademik terintergrasi dan dapat di custom sesuai kebutuhan madrasah Siakad Enterprise ini akan memberikan kemudahan dan keamanan pengolaan data madrasah diniah. Sebagus apapun system tanpa ada pendampingan terhadap system itu berjalan, maka usaha yang dilakukan dari awal mulai dari tahap analisis, desain, koding, testing akan menjadi sia, oleh karena itu perlu adanya pendampingan terhadap system dengan menggunakan metode kualitatif.

\section{Metode}

Banyak sekali metode bagaimana mentransfer ilmu bagaimana mendampingi user agar mahir dalam mengoperasikan Sistem Akademik Berbasis Web, adapun metode untuk pembelajaran diantaranya:

1. Diskusi Umum

Metode ini bertujuan untuk tukar menukar gagasan, pemikiran, informasi/ pengalaman diantara peserta, sehingga dicapai kesepakatan pokok-pokok pikiran (gagasan, kesimpulan). Untuk mencapai kesepakatan tersebut, para peserta dapat saling beradu argumentasi untuk meyakinkan peserta lainnya. Kesepakatan pikiran inilah yang kemudian ditulis sebagai hasil diskusi. Diskusi biasanya digunakan sebagai bagian yang tak terpisahkan dari penerapan berbagai metode lainnya, seperti: penjelasan (ceramah), curah pendapat, diskusi kelompok, permainan, dan lain-lain. 


\section{Brainstorming}

Metode curah pendapat adalah suatu bentuk diskusi dalam rangka menghimpun gagasan, pendapat, informasi, pengetahuan, pengalaman, dari semua peserta. Berbeda dengan diskusi, dimana gagasan dari seseorang dapat ditanggapi (didukung, dilengkapi, dikurangi, atau tidak disepakati) oleh peserta lain, pada penggunaan metode curah pendapat pendapat orang lain tidak untuk ditanggapi. Tujuan curah pendapat adalah untuk membuat kompilasi (kumpulan) pendapat, informasi, pengalaman semua peserta yang sama atau berbeda. Hasilnya kemudian dijadikan peta informasi, peta pengalaman, atau peta gagasan (mindmap) untuk menjadi pembelajaran bersama

3. Diskusi Kelompok

Sama seperti diskusi, diskusi kelompok adalah pembahasan suatu topik dengan cara tukar pikiran antara dua orang atau lebih, dalam kelompok-kelompok kecil, yang direncanakan untuk mencapai tujuan tertentu. Metode ini dapat membangun suasana saling menghargai perbedaan pendapat dan juga meningkatkan partisipasi peserta yang masih belum banyak berbicara dalam diskusi yang lebih luas. Tujuan penggunaan metode ini adalah mengembangkan kesamaan pendapat atau kesepakatan atau mencari suatu rumusan terbaik mengenai suatu persoalan.Setelah diskusi kelompok, proses dilanjutkan dengan diskusi pleno. Pleno adalah istilah yang digunakan untuk diskusi kelas atau diskusi umum yang merupakan lanjutan dari diskusi kelompok yang dimulai dengan pemaparan hasil diskusi kelompok

4. Role-Play

Bermain peran pada prinsipnya merupakan metode untuk 'menghadirkan' peranperan yang ada dalam dunia nyata ke dalam suatu 'pertunjukan peran' di dalam kelas/pertemuan, yang kemudian dijadikan sebagai bahan refleksi agar peserta memberikan penilaian terhadap. Misalnya: menilai keunggulan maupun kelemahan masingmasing peran tersebut, dan kemudian memberikan saran/ alternatif pendapat bagi pengembangan peran-peran tersebut. Metode ini lebih menekankan terhadap masalah yang diangkat dalam 
'pertunjukan', dan bukan pada kemampuan pemain dalam melakukan permainan peran

5. Simulasi

Metode simulasi adalah bentuk metode praktek yang sifatnya untuk mengembangkan ketermpilan peserta belajar (keterampilan mental maupun fisik/teknis). Metode ini memindahkan suatu situasi yang nyata ke dalam kegiatan atau ruang belajar karena adanya kesulitan untuk melakukan praktek di dalam situasi yang sesungguhnya.

6. Demontrasi

Demonstrasi adalah metode yang digunakan untuk membelajarkan peserta dengan cara menceritakan dan memperagakan suatu langkah-langkah pengerjaan sesuatu. Demonstrasi merupakan praktek yang diperagakan kepada peserta. Karena itu, demonstrasi dapat dibagi menjadi dua tujuan: demonstrasi proses untuk memahami langkah demi langkah; dan demonstrasi hasil untuk memperlihatkan atau memperagakan hasil dari sebuah proses.Biasanya, setelah demonstrasi dilanjutkan dengan praktek oleh peserta sendiri. Sebagai hasil, peserta akan memperoleh pengalaman belajar langsung setelah melihat, melakukan, dan merasakan sendiri. Tujuan dari demonstrasi yang dikombinasikan dengan praktek adalah membuat perubahan pada rana keterampilan.

Dalam penelitian ini metode transfer ilmu untuk user menggunakan metode simulasi, dengan mensimulasikan system bagaiamana cara menggunakan aplikasi siakad berbasis web diharapkan peserta dapat menjalan aplikasi dengan benar dan baik.

\section{Hasil}

Setelah peneliti mengumpulkan data melalui wawancara, observasi, dan dokumentasi, setelah data tersebut sudah direduksi dan dipaparkan, maka selanjutnya ialah melakukan analisis data yang bertujuan untuk memberikan penjelasan lebih lanjut tentang hasil penelitian. 
Adanya langkah penerapan pembelajaran yang diperinci dengan pembagian durasi waktu per segmen kegiatan merupakan salah satu faktor penentu akan keberhasilan peserta latihan dalam memaksimalkan waktu belajar system siakad online.

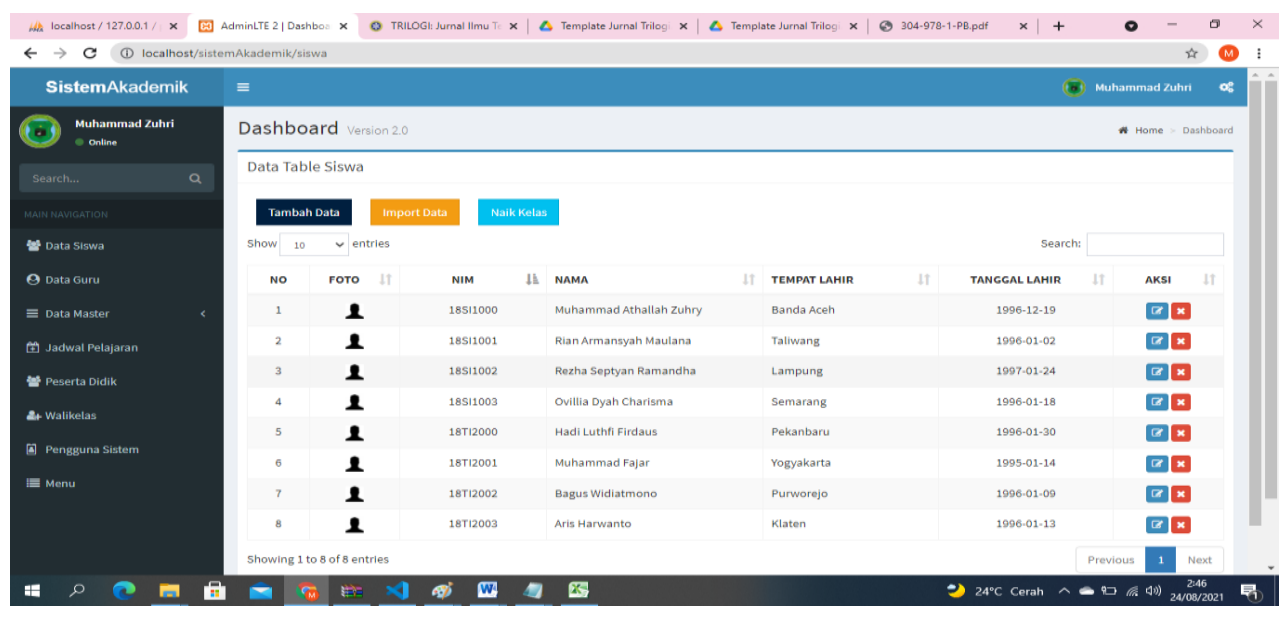

Gambar 1 Aplikasi Siakad berbasis Web
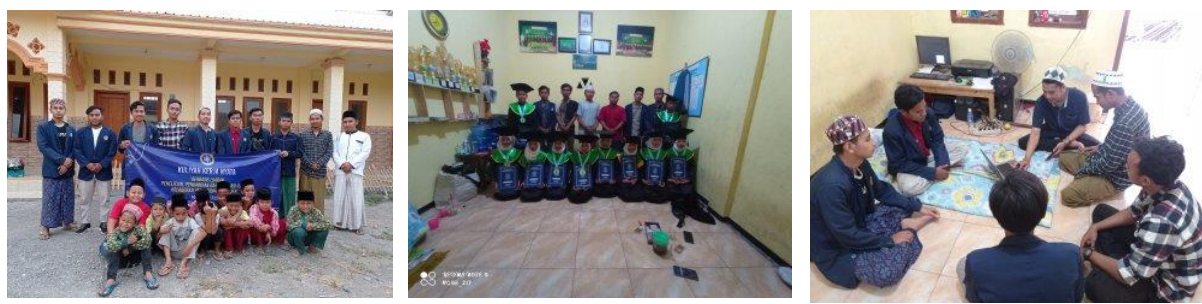

Gambar2 Foto Kegiatan PKM

\section{Pembahasan}

Kemampuan seseorang dalam memahami dan menyerap pelajaran tentu berbeda-beda. Ada yang cepat, sedang, dan ada pula lambat. Bukan hanya kecepatan yang berbeda tetapi juga cara memperoses informasi tentu berbeda pula. Cara memproses infromasi itu disebut sebagai gaya belajar.

Pengetahuan dan pemahaman terhadap cara mengoperasikan system siakad berbasis web dapat memudahkan peserta melakukan interaksi dan pembuatan laporan rekapan terkait data akademik sekolah. Pengetahuan dan pemahaman yang dibangun dalam modalitas belajar ini meliputi ciri tiap modalitas belajar, cara mengajar untuk tiap-tiap modalitas dan strategi yang disarankan dalam kegiatan pelatihan. Modalitas belajar itu sendiri merupakan 
cara seseorang dalam menyerap informasi lewat indra yang mereka milikinya. Cara cepat otak untuk menyerap informasi, berinteraksi dan berkomunikasi.

\section{Kesimpulan}

Adapun kesimpulan dari penelitian terkait pendampingan metode pelatihan ini adalah Dihasilkan aplikasi yang lebih powerfull karena penggunaan menjadi lebih mudah karena user mengetahui cara kerja sistem karena adanya pelatihan dengan menggunakan metode simulasi

\section{Referensi}

Alwasilah, Chaedar. 2017. Pokoknya Kualitatif: Dasar-Dasar Merancang dan Melakukan Penelitian Kualitatif. Bandung: Dunia Pustaka Jaya.

Gazali, Marlina. (2013). Optimalisasi Peran Lembaga Pendidikan Untuk Mencerdaskan Bangsa. Jurnal Al-Ta'dib

Malik, Kamil., \& Faid, Mochammad. (2016). Prediksi Prestasi Siswa Smp Nurul Jadid Menggunakan Algoritma C4.5. NJCA: Nusantara Journal of Computers and its Applications.

Purnomo, Dwi. (2017). Model Prototyping Pada Pengembangan Sistem Informasi. JIMP: Jurnal Informatika Merdeka Pasuruan

Ardy Wiyani, Novan. 2010. Inovasi Kurikulum dan Pembeljaaran PAI SMA Berbasis Pendidikan Karakter. Yogyakarta: A-Ruzz Media.

Arifin, Zainal. 2012. Penelitian Pendidikan: Metode dan Paradigma Baru. Bandung: Remaja Rosdakarya. 